\title{
Controlling alkyne reactivity by means of a copper-catalyzed radical reaction system for the synthesis of functionalized quaternary carbons
}

\author{
Goki Hirata, Yu Yamane, Naoya Tsubaki, Reina Hara and Takashi Nishikata*
}

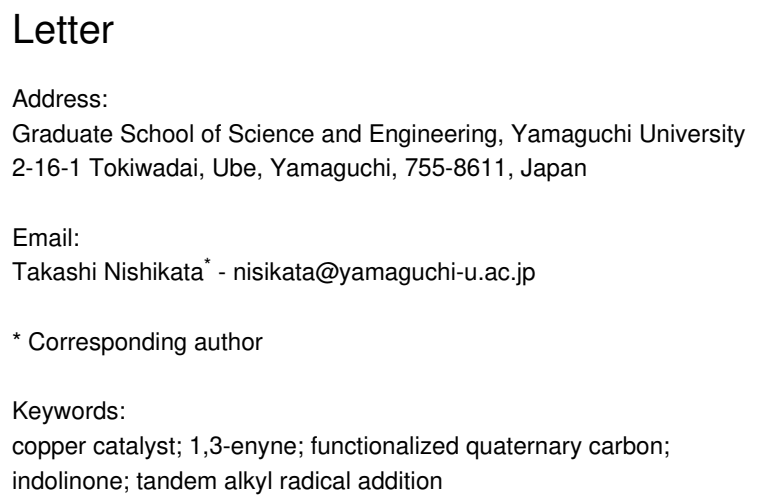

\author{
Beilstein J. Org. Chem. 2020, 16, 502-508. \\ doi:10.3762/bjoc. 16.45 \\ Received: 17 December 2019 \\ Accepted: 13 March 2020 \\ Published: 26 March 2020 \\ This article is part of the thematic issue "Copper-catalyzed reactions for \\ organic synthesis". \\ Guest Editor: G. Evano \\ (C) 2020 Hirata et al.; licensee Beilstein-Institut. \\ License and terms: see end of document.
}

\begin{abstract}
A terminal alkyne is one of the most useful reactants for the synthesis of alkyne and alkene derivatives. Because an alkyne undergoes addition reaction at a $\mathrm{C}-\mathrm{C}$ triple bond or cross-coupling at a terminal $\mathrm{C}-\mathrm{H}$ bond. Combining those reaction patterns could realize a new reaction methodology to synthesize complex molecules including $\mathrm{C}-\mathrm{C}$ multiple bonds. In this report, we found that the reaction of 3 equivalents of terminal alkyne $\mathbf{1}$ (aryl substituted alkyne) and an $\alpha$-bromocarbonyl compound $\mathbf{2}$ (tertiary alkyl radical precursor) undergoes tandem alkyl radical addition/Sonogashira coupling to produce 1,3-enyne compound $\mathbf{3}$ possessing a quaternary carbon in the presence of a copper catalyst. Moreover, the reaction of $\alpha$-bromocarbonyl compound $\mathbf{2}$ and an alkyne $\mathbf{4}$ possessing a carboxamide moiety undergoes tandem alkyl radical addition/C-H coupling to produce indolinone derivative $\mathbf{5}$.
\end{abstract}

\section{Introduction}

Terminal alkynes are undoubtedly useful functional groups for organic synthesis, and they can undergo a variety of reactions [1]. The $\mathrm{C}-\mathrm{C}$ triple bond of an alkyne is suitable for addition reactions, whereas the terminal hydrogen atom is a good target for cross-coupling by using Sonogashira and related coupling reactions [2-4]. Although there are many reports on alkyne transformations, one recent development in this area has been the reaction of alkynes with tertiary alkyl electrophiles to produce functionalized quaternary carbon atoms via addition [5-10] or coupling [11-16].

Recently, we have prepared quaternary carbon centers via radical reactions by using $\alpha$-bromocarbonyl compounds (a tertiary alkyl source) and olefins or heteroatoms in the presence of a copper catalyst [17-19]. During our studies, we found that combinations of alkynes and tertiary alkyl radicals generated 
from the reaction of a copper catalyst and an $\alpha$-bromocarbonyl compound can undergo i) Sonogashira type couplings via an alkynyl-Cu intermediate [20], ii) cis-hydro tertiary alkylations via 1-alkenyl-Cu [21], and iii) trans-hydro tertiary alkylations via atom-transfer radical addition (ATRA) [21] (Scheme 1, i-iii). Therefore, we postulated that if we could control the reactivities of the alkynyl-Cu and ATRA adducts, a tandem tertiary alkylation followed by an alkynylation could occur to produce a 1,3-enyne possessing a quaternary carbon center with good regio- and stereoselectivity (Scheme 1, this work). Similarly, Zhu's group has reported that the reaction of an alkyne and an $\alpha$-bromocarbonyl compound furnishes a highly functionalized 1,3-enyne compound via ATRA followed by an alkynylation reaction [22], but both $\mathrm{Pd}$ and $\mathrm{Cu}$ are required as catalysts in that case. Our methodology can realize a Pd-free catalyst system to prepare complex quaternary carbon atoms. Herein, we report the $\mathrm{Cu}$-catalyzed control of the reactivity of an alkyne (addition and coupling) undergoing tandem tertiary alkylation and alkynylation to produce a 1,3-enyne containing a quaternary carbon center with good regio- and stereoselectivity.

\section{Results and Discussion}

In our preliminary research, we tried various $\mathrm{Cu}$ salts, including $\mathrm{CuI}, \mathrm{CuBr}, \mathrm{CuCl}, \mathrm{CuOAc}$, and CuOTf, and ligands, including $\mathrm{PPh}_{3}, 1,10$-phenanthroline (1,10-Phen), $N, N, N^{\prime}, N^{\prime \prime}, N^{\prime \prime}$-pentamethyldiethylenetriamine, and tris(2-pyridylmethyl)amine, in the reaction of phenylacetylene (1a) and $\alpha$-bromoester 2a. From these experiments, $\mathrm{CuBr}$ and 1,10-Phen acted as a good catalyst system for obtaining 1,3-enyne 3a in $62 \%$ yield with good regio- and stereoselectivity (Table 1 , entry 1 ). On the basis of this preliminary result, we also tried other conditions. Toluene was very effective in our previous reaction system [17] but was not effective at all in this case (Table 1 , entry 2 ). The reaction without $\mathrm{NaI}$ resulted in the formation of $\mathbf{3 a - B r}$ in $30 \%$ yield, instead of 3a (Table 1, entry 3). If KI was used instead of NaI, the yield of 3a decreased (Table 1, entry 4). We will discuss the proposed reaction mechanism later in the text, but the formation of 3a-I via ATRA could be important for the alkynylation reaction. Generally, the Sonogashira coupling requires both a Pd catalyst and a Cu co-catalyst [2-4]. However, couplings with terminal alkynes can be carried out in the absence of the Pd catalyst [23-32]; this is the so-called Castro-Stephens reaction [33]. The effect of the base was very important for producing the main product 3a (Table 1, entries 5-8). If the reaction was performed in the presence of a base other than $\mathrm{Cs}_{2} \mathrm{CO}_{3}$, a decreased yield of $\mathbf{3 a}$ was observed. Finally, an increased amount of catalyst was effective for obtaining the highest yield (Table 1, entry 9). The total yield was moderate, but the yields for each step of this two-step tandem reaction system (ATRA followed by Castro-Stephens coupling) should be over $80 \%$.

Under the optimized conditions, the reactivities of alkynes $\mathbf{1}$ and $\alpha$-bromocarbonyl compounds $\mathbf{2}$ were examined (Figure 1). The two-step tandem alkyne transformation produced various 1,3-enynes $\mathbf{3}$ with concomitant formation of ATRA adducts as side-products. It was very difficult to separate the products by silica-gel column chromatography; therefore, we are reporting the ${ }^{1} \mathrm{H}$ NMR and GPC yields of $\mathbf{3}$. (The pure products were obtained by gel permeation chromatography (GPC).) For example, $\alpha$-bromocarbonyl compounds 2 possessing various degrees of steric bulkiness (ethyl groups) at the carbonyl $\alpha$-position or a

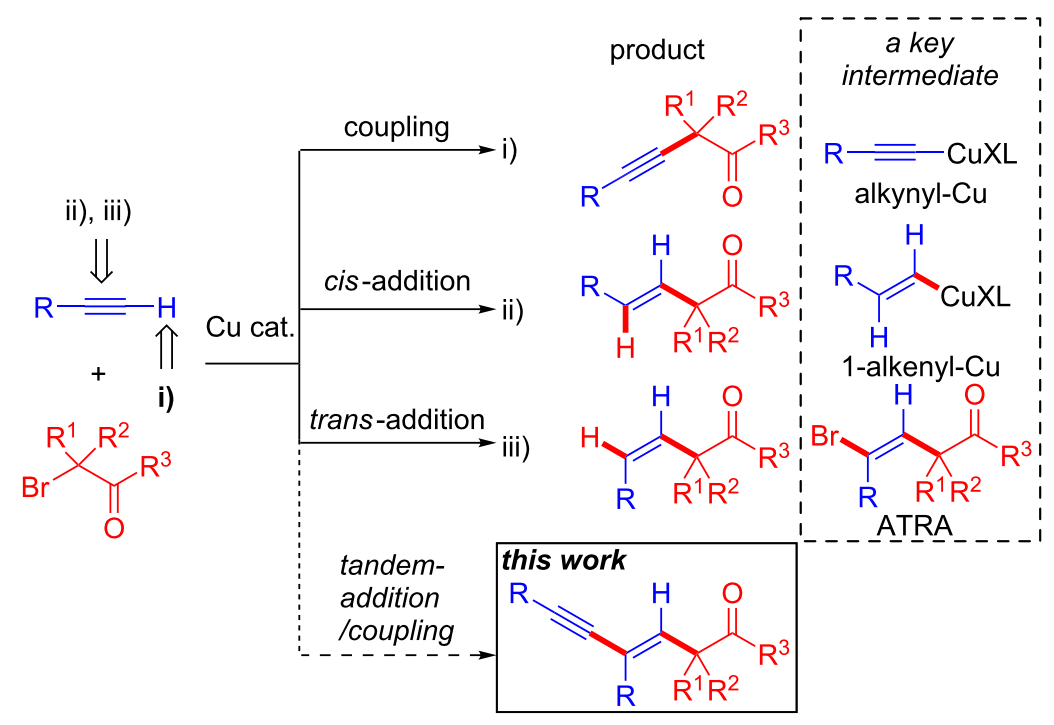


Table 1: Optimization. ${ }^{a}$
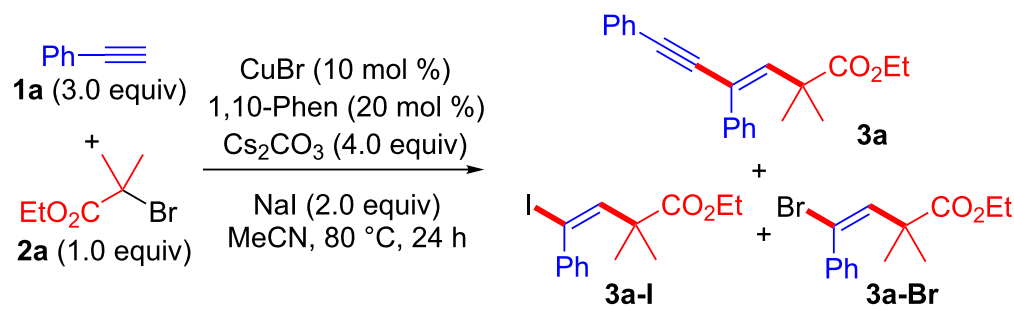

\begin{tabular}{|c|c|c|c|c|}
\hline entry & changes from standard conditions & $3 \mathbf{a}(\%)$ & 3a-I (\%) & $3 a-B r(\%)$ \\
\hline 1 & none & 62 & 10 & trace \\
\hline 2 & toluene instead of $\mathrm{MeCN}$ & trace & - & - \\
\hline 3 & without Nal & $<5$ & 0 & 30 \\
\hline 4 & $\mathrm{KI}$ instead of $\mathrm{Nal}$ & 30 & 7 & 7 \\
\hline 5 & Hunig's base instead of $\mathrm{Cs}_{2} \mathrm{CO}_{3}$ & trace & 60 & trace \\
\hline 6 & $\mathrm{iPr}_{2} \mathrm{NH}$ instead of $\mathrm{Cs}_{2} \mathrm{CO}_{3}$ & trace & 65 & trace \\
\hline 7 & $\mathrm{~K}_{2} \mathrm{CO}_{3}$ instead of $\mathrm{Cs}_{2} \mathrm{CO}_{3}$ & 6 & 58 & trace \\
\hline 8 & $\mathrm{~K}_{3} \mathrm{PO}_{4}$ instead of $\mathrm{Cs}_{2} \mathrm{CO}_{3}$ & 26 & 20 & trace \\
\hline 9 & $15 \mathrm{~mol} \% \mathrm{CuBr}$ and $30 \mathrm{~mol} \%$ 1,10-Phen & $66(52)^{b}$ & 7 & trace \\
\hline
\end{tabular}

${ }^{\mathrm{a} C}$ Conducted at $80{ }^{\circ} \mathrm{C}$ for $24 \mathrm{~h}$ in $\mathrm{MeCN}$ with $\mathrm{CuBr}$ (10 mol \%), 1,10-Phen (20 mol \%), $\mathrm{Cs}_{2} \mathrm{CO}_{3}$ (4.0 equiv), $\mathrm{Nal}$ (2.0 equiv), 1a (3.0 equiv) and 2a (1.0 equiv). Yields were determined by ${ }^{1} \mathrm{H}$ NMR analysis. ${ }^{\mathrm{b}} \mathrm{GPC}$ yield.

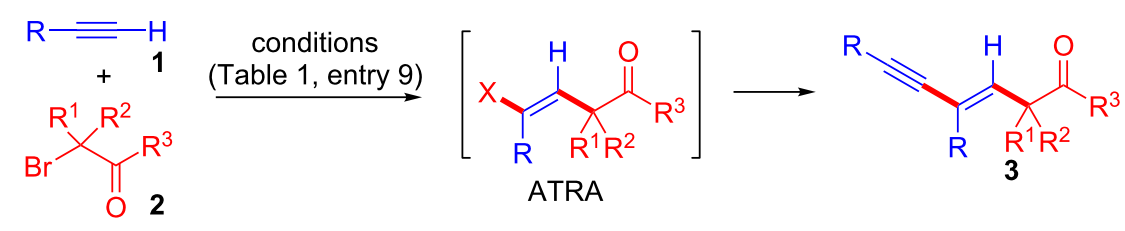

yields of products 3

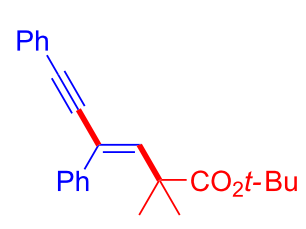

3b: $52 \%$ (GPC yield: 49\%)

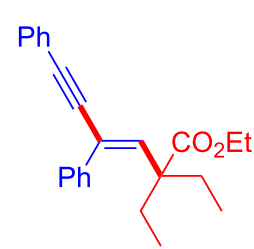

3c: $46 \%$ (GPC yield: $39 \%$ )

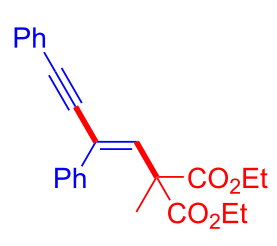

3d: $40 \%$

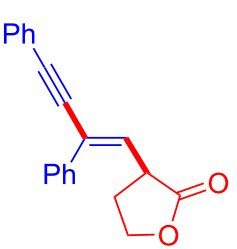

3e: $53 \%$

(GPC yield: 48\%)

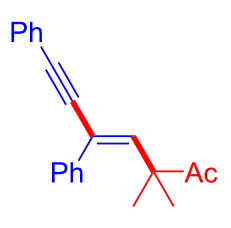

3f: $52 \%$

(GPC yield: 44\%)

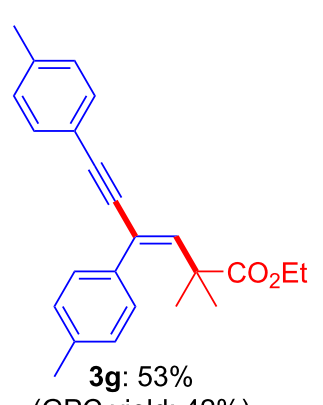

(GPC yield: $42 \%$ )

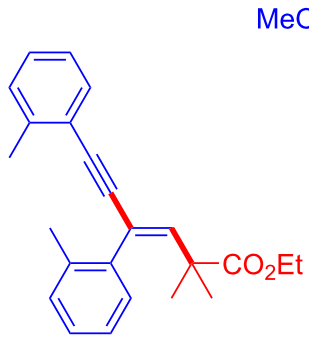

3h: $58 \%$ (GPC yield: $48 \%$ )

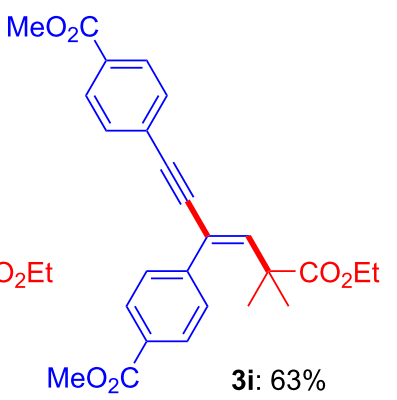

(GPC yield: $51 \%$ )

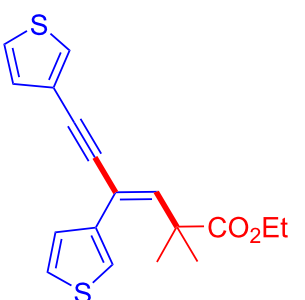

$3 j: 48 \%$

(isolated yield: $53 \%$ )

Figure 1: Substrate scope of 1 and 2. ${ }^{2} \mathrm{Conducted}$ at $80{ }^{\circ} \mathrm{C}$ for $24 \mathrm{~h}$ in $\mathrm{MeCN}$ with $\mathrm{CuBr}(10 \mathrm{~mol} \%), 1,10-\mathrm{Phen}(20 \mathrm{~mol} \%), \mathrm{Cs}_{2} \mathrm{CO}_{3}(4.0$ equiv), $\mathrm{Nal}$ (2.0 equiv), 1 (3.0 equiv) and 2 (1.0 equiv). Yields were determined by ${ }^{1} \mathrm{H}$ NMR analysis. 
tert-butyl ester group reacted with $\mathbf{1 a}$ to produce $\mathbf{3 b}$ and $\mathbf{3 c}$ in moderate yields. Bromomalonate, bromolactone, and bromoketone derivatives resulted in the formation of $\mathbf{3 d}, \mathbf{3 e}$, and $\mathbf{3 f}$ in $40 \%, 53 \%$, and $52 \%$ yield, respectively. Ortho and meta substituted arylalkynes $\mathbf{1}$ reacted with $\mathbf{2 a}$ to produce $\mathbf{3 g}$ and $\mathbf{3 h}$, respectively. An arylalkyne 1 possessing an electron-withdrawing group (ester) yielded $\mathbf{3 i}$ without affecting the reactivity of 2 . Sulfur functional groups tend to decrease the catalytic activity of copper salts, but thienyl-substituted alkyne 1 reacted with $\mathbf{2 a}$ to produce $\mathbf{3 j}$ in $48 \%$ yield.

Although the exact reaction mechanism is currently unclear, one possibility involves a radical pathway including cross-coupling with an alkynyl copper species (Scheme 2). After the generation of $\mathbf{A}$, addition of $\mathbf{A}$ to $\mathbf{1}$ takes place to give the radical intermediate $\mathbf{B}$. This then reacts with the $\mathrm{Cu}$ (II) species to produce intermediate $\mathbf{C}$, with concomitant formation of a $\mathrm{Cu}(\mathrm{I})$ species. The brominated intermediate $\mathbf{C}$ undergoes a cross-coupling reaction with the alkynyl copper species to give the desired product 3 . We have detected brominated intermediate $\mathbf{C}$ during the reaction. We have also examined the reaction between $\mathbf{3 a - B r}$ (intermediate $\mathbf{C}$ ) and the alkynyl copper species (1a-Cu) (Scheme 3). The result showed that 3a-Br reacted with the alkynyl copper species to produce the desired product 3a in reasonable yield. This reaction should be a Sonogashira coupling without a Pd catalyst $[23,24,30]$.

Interestingly, if the reaction of $\mathbf{2 a}$ and electron-deficient alkyne 4a was performed under the conditions shown in Table 1, entry 9, the $\mathrm{C}-\mathrm{H}$ cyclized product $\mathbf{5 a}$ was obtained instead of $\mathbf{3 k}$. In this case, an alkyl radical addition followed by $\mathrm{C}-\mathrm{H}$ cyclization via an alkenyl radical intermediate could be occur (Scheme 4). A Pd-catalyzed cascade reaction $(\mathrm{C}-\mathrm{C}$ bond formation/C-H cyclization process) of $\mathrm{N}$-arylpropynamide $\mathbf{4}$ for the preparation of indolinone derivatives $\mathbf{5}$ was previously reported by Li's group $[34,35]$. In another report on $\mathrm{C}-\mathrm{H}$ cyclization by Lei's group, Ni-catalyzed aromatic $\mathrm{C}-\mathrm{H}$ alkylation occurs via a radical reaction [36]. Both cases were helpful in our development of the current $\mathrm{Cu}$-catalyzed cascade $\mathrm{C}-\mathrm{H}$ cyclization system.

After careful optimization, we found that CuI, 1,10-Phen, $\mathrm{Cy}_{2} \mathrm{NMe}$ as a base, and 1,4-dioxane were effective for obtaining the best yields of products 5 (Figure 2). In this examination, product isolation was difficult because of the formation of stereoisomers ( $E$ and $Z$ stereoisomers of $\mathbf{5}$ ). The yields shown in

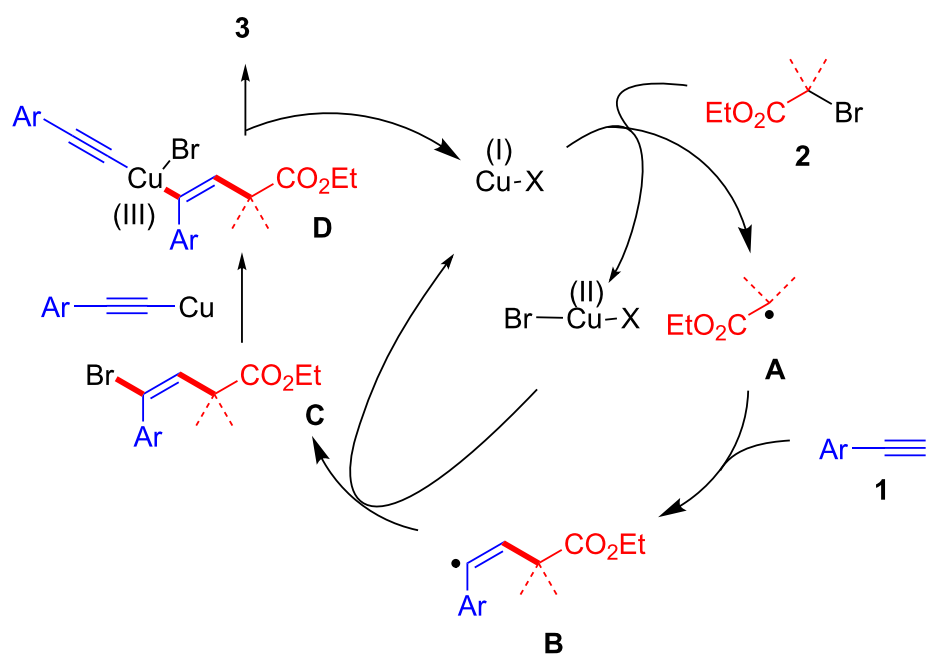

Scheme 2: Proposed mechanism.

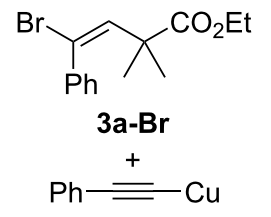

1a-Cu: 1 equiv

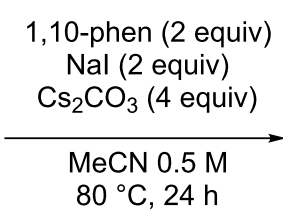

$80^{\circ} \mathrm{C}, 24 \mathrm{~h}$ 3a: $51 \% \quad 3 a-B r: 17 \%$<smiles>CCOC(=O)C(C)(C)/C=C(/I)Pc1ccccc1</smiles>

3a-I: $16 \%$ 


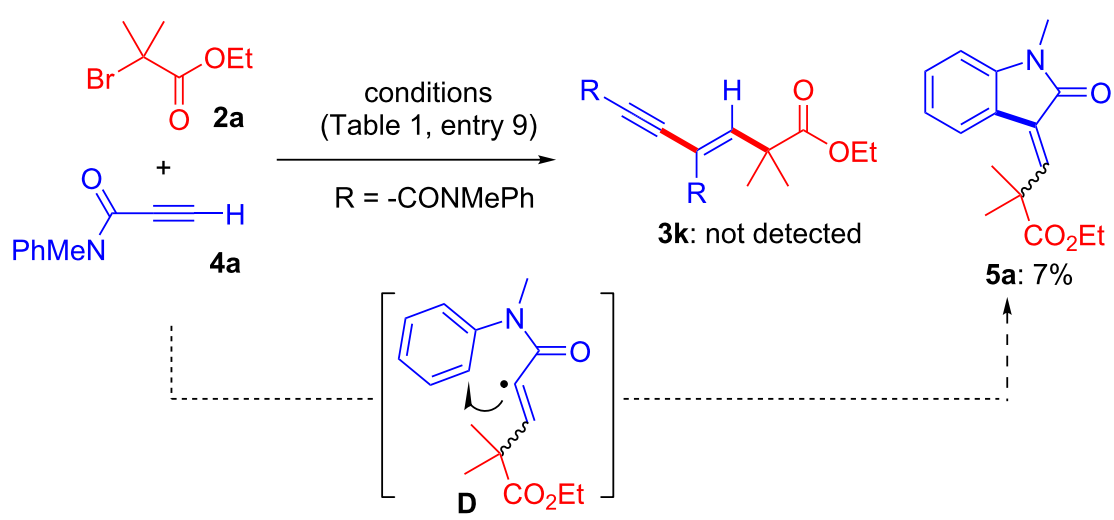

Scheme 4: Reaction of $2 a$ and $4 a$.

Figure 2 were including isomers (We also put yield of pure $E-5$ as an NMR yield.). Although the chemical yields of $\mathbf{5}$ were moderate, the stereoselectivities in this reaction were good (the major stereoisomers of $\mathbf{5}$ produced were $E$ ). We tested compounds 2 possessing acyclic and cyclic structures and com- pounds 4 possessing $\mathrm{MeO}, \mathrm{F}$, and $\mathrm{N}$-Et moieties as substrates for the reaction; however, no big differences were observed. The $\mathrm{C}-\mathrm{H}$ cyclized products were not obtained from the reaction of compound $\mathbf{4}$ if it did not possess an alkyl substituent on the nitrogen atom of the amide bond.

\section{Cul $(10 \mathrm{~mol} \%)$

\begin{tabular}{|c|c|c|}
\hline & & 1,10 -Phen $(10 \mathrm{~mol} \%)$ \\
\hline iiv & $3.0 \mathrm{e}$ & $\begin{array}{r}\mathrm{Cy}_{2} \mathrm{NM} \\
\text { 1,4-dioxan }\end{array}$ \\
\hline
\end{tabular}

yields of products 5<smiles>CCOC(=O)C(C)(C)C=C1C(=O)N(C)c2ccccc21</smiles>

5a: $69 \%$

$(E: Z=90: 10)$ isolated yield: $70 \%$ b<smiles>CCOC(=O)C(C)(C)/C=C1/C(=O)N(C)c2ccc(C)cc21</smiles>

5b: $63 \%$ $(E: Z=95: 5)$ isolated yield: $62 \%$<smiles>CCOC(C)(C)C=C1C(=O)N(C)c2ccc(F)cc21</smiles>

5d: $54 \%$ $(E: Z=94: 6)$ $(E: Z=90: 10)$ isolated yield: $63 \%^{\mathrm{b}}$ isolated yield: $58 \%^{\mathrm{b}}$<smiles>CCOC(=O)C1(C=C2C(=O)N(C)c3ccccc32)CCC1</smiles>

5e: $60 \%$

(47\% isolated yield of $E-5 e$, $E: Z=94: 6$ )<smiles>COC(=O)C1(/C=C2/ON(C)c3ccccc32)CCCCC1</smiles>

5f: $60 \%$

$(E: Z=92: 8)$ isolated yield: $62 \%{ }^{\mathrm{b}}$<smiles>CN1C(=O)/C(=C/C(C)(C)C(=O)OCc2ccc(C(C)(C)C)cc2)c2ccccc21</smiles>

$(E: Z=90: 10)$ isolated yield: $60 \%^{\mathrm{b}}$<smiles>CN1C(=O)/C(=C/C(C)(C)C(=O)OCc2ccc3ccccc3c2)c2ccccc21</smiles>

$(E: Z=90: 10)$ isolated yield: $62 \%$ b<smiles>CCOC(=O)C(C)(C)C=C1C(=O)N(CC)c2ccccc21</smiles>

5i: $65 \%$

$(E: Z=95: 5)$ isolated yield: $73 \%$ b 


\section{Conclusion}

In summary, we have developed two types of tandem reactions catalyzed by a copper salt. The reaction of 2-bromocarbonyl compounds and aryl-substituted alkynes underwent alkyl radical addition at a $\mathrm{C}-\mathrm{C}$ triple bond followed by Sonogashira coupling to produce 1,3-enyne compounds. On the other hand, the reaction with alkyne possessing a carboxamide moiety underwent tandem alkyl radical addition at the $\mathrm{C}-\mathrm{C}$ triple bond followed by $\mathrm{C}-\mathrm{H}$ coupling to produce indolinone derivatives. These results could suggest new aspects of alkyne transformations in a copper catalyzed alkyl radical reaction system.

\section{Supporting Information}

\section{Supporting Information File 1}

Experimental procedures, compound characterization data, and NMR spectra.

[https://www.beilstein-journals.org/bjoc/content/ supplementary/1860-5397-16-45-S1.pdf]

\section{Funding}

We warmly thank Yamaguchi university (TN), the Naito foundation, and JSPS KAKENHI Grant Number JP 18H04262(TN) in Precisely Designed Catalysts with Customized Scaffolding.

\section{ORCID ${ }^{\circledR}$ iDs}

Goki Hirata - https://orcid.org/0000-0002-2532-9959

Takashi Nishikata - https://orcid.org/0000-0002-2659-4826

\section{References}

1. Trost, B. M.; Li, C.-J. Modern Alkyne Chemistry: Catalytic and AtomEconomic Transformations; Wiley-VCH: Weinheim, Germany, 2015.

2. Chinchilla, R.; Nájera, C. Chem. Rev. 2007, 107, 874-922. doi:10.1021/cr050992x

3. Sonogashira, K.; Tohda, Y.; Hagihara, N. Tetrahedron Lett. 1975, 16, 4467-4470. doi:10.1016/s0040-4039(00)91094-3

4. Liu, W.; Li, L.; Li, C.-J. Nat. Commun. 2015, 6, 6526. doi:10.1038/ncomms7526

5. Liu, W.; Chen, Z.; Li, L.; Wang, H.; Li, C.-J. Chem. - Eur. J. 2016, 22, 5888-5893. doi:10.1002/chem.201600219

6. Beringer, F. M.; Galton, S. A. J. Org. Chem. 1965, 30, 1930-1934. doi:10.1021/j001017a053

7. Ochiai, M.; Kunishima, M.; Nagao, Y.; Fuji, K.; Shiro, M.; Fujita, E. J. Am. Chem. Soc. 1986, 108, 8281-8283. doi:10.1021/ja00286a037

8. Bachi, M. D.; Bar-Ner, N.; Crittell, C. M.; Stang, P. J.; Williamson, B. L. J. Org. Chem. 1991, 56, 3912-3915. doi:10.1021/jo00012a025

9. Fernández González, D.; Brand, J. P.; Waser, J. Chem. - Eur. J. 2010, 16, 9457-9461. doi:10.1002/chem.201001539

10. Brand, J. P.; Waser, J. Chem. Soc. Rev. 2012, 41, 4165-4179. doi:10.1039/c2cs35034c

11. Dong, W.; Yuan, Y.; Gao, X.; Keranmu, M.; Li, W.; Xie, X.; Zhang, Z. Org. Lett. 2018, 20, 5762-5765. doi:10.1021/acs.orglett.8b02463
12. Gao, Y.; Zhang, P.; Li, G.; Zhao, Y. J. Org. Chem. 2018, 83, 13726-13733. doi:10.1021/acs.joc.8b02001

13. Liu, B.; Yu, J.-X.; Li, Y.; Li, J.-H.; He, D.-L. Org. Lett. 2018, 20 , 2129-2132. doi:10.1021/acs.orglett.8b00236

14. Gao, Y.; Zhang, P.; Ji, Z.; Tang, G.; Zhao, Y. ACS Catal. 2017, 7, 186-190. doi:10.1021/acscatal.6b03033

15. Che, C.; Huang, Q.; Zheng, H.; Zhu, G. Chem. Sci. 2016, 7, 4134-4139. doi:10.1039/c5sc04980f

16. Cheung, C. W.; Zhurkin, F. E.; Hu, X. J. Am. Chem. Soc. 2015, 137, 4932-4935. doi:10.1021/jacs.5b01784

17. Nishikata, T.; Noda, Y.; Fujimoto, R.; Sakashita, T. J. Am. Chem. Soc. 2013, 135, 16372-16375. doi:10.1021/ja409661n

18. Nishikata, T.; Ishida, S.; Fujimoto, R. Angew. Chem., Int. Ed. 2016, 55, 10008-10012. doi:10.1002/anie.201603426

19. Ishida, S.; Takeuchi, K.; Taniyama, N.; Sunada, Y.; Nishikata, T. Angew. Chem., Int. Ed. 2017, 56, 11610-11614. doi:10.1002/anie.201706293

20. Yamane, Y.; Miwa, N.; Nishikata, T. ACS Catal. 2017, 7, 6872-6876. doi:10.1021/acscatal.7b02615

21. Nakamura, K.; Nishikata, T. ACS Catal. 2017, 7, 1049-1052. doi:10.1021/acscatal.6b03343

22. Che, C.; Zheng, H.; Zhu, G. Org. Lett. 2015, 17, 1617-1620. doi:10.1021/acs.orglett.5b00546

23. Okuro, K.; Furuune, M.; Enna, M.; Miura, M.; Nomura, M. J. Org. Chem. 1993, 58, 4716-4721. doi:10.1021/jo00069a040

24. Gujadhur, R. K.; Bates, C. G.; Venkataraman, D. Org. Lett. 2001, 3, 4315-4317. doi:10.1021/ol0170105

25. Thathagar, M. B.; Beckers, J.; Rothenberg, G. Green Chem. 2004, 6, 215-218. doi:10.1039/b401586j

26. Ma, D.; Liu, F. Chem. Commun. 2004, 1934-1935. doi:10.1039/b407090a

27. Wang, Y. F.; Deng, W.; Liu, L.; Guo, Q. X. Chin. Chem. Lett. 2005, 16, 1197-1200.

28. Saejueng, P.; Bates, C. G.; Venkataraman, D. Synthesis 2005, 1706-1712. doi:10.1055/s-2005-869893

29. Xie, Y.-X.; Deng, C.-L.; Pi, S.-F.; Li, J.-H.; Yin, D.-L. Chin. J. Chem. 2006, 24, 1290-1294. doi:10.1002/cjoc.200690240

30. Li, J.-H.; Li, J.-L.; Wang, D.-P.; Pi, S.-F.; Xie, Y.-X.; Zhang, M.-B.; Hu, X.-C. J. Org. Chem. 2007, 72, 2053-2057. doi:10.1021/jo0623742

31. Tang, B.-X.; Wang, F.; Li, J.-H.; Xie, Y.-X.; Zhang, M.-B. J. Org. Chem. 2007, 72, 6294-6297. doi:10.1021/jo070538o

32. Guan, J. T.; Yu, G.-A.; Chen, L.; Weng, T. Q.; Yuan, J. J.; Liu, S. H. Appl. Organomet. Chem. 2009, 23, 75-77. doi:10.1002/aoc.1474

33. Stephens, R. D.; Castro, C. E. J. Org. Chem. 1963, 28, 3313-3315. doi:10.1021/jo01047a008

34. Tang, S.; Peng, P.; Zhong, P.; Li, J.-H. J. Org. Chem. 2008, 73, 5476-5480. doi:10.1021/j08008808

35. Jiang, T.-S.; Tang, R.-Y.; Zhang, X.-G.; Li, X.-H.; Li, J.-H. J. Org. Chem. 2009, 74, 8834-8837. doi:10.1021/jo901963g

36. Liu, C.; Liu, D.; Zhang, W.; Zhou, L.; Lei, A. Org. Lett. 2013, 15, 6166-6169. doi:10.1021/ol403021p 


\section{License and Terms}

This is an Open Access article under the terms of the Creative Commons Attribution License

(http://creativecommons.org/licenses/by/4.0). Please note that the reuse, redistribution and reproduction in particular requires that the authors and source are credited.

The license is subject to the Beilstein Journal of Organic Chemistry terms and conditions:

(https://www.beilstein-journals.org/bjoc)

The definitive version of this article is the electronic one which can be found at:

doi:10.3762/bjoc. 16.45 